\title{
Dopaminergic Role in Regulating Neurophysiological Markers of Sleep Homeostasis in Humans
}

\author{
Sebastian C. Holst, ${ }^{1,3}$ Alessia Bersagliere, ${ }^{1}$ Valérie Bachmann, ${ }^{1,3}$ Wolfgang Berger, ${ }^{2,3,4}$ Peter Achermann, ${ }^{1,3,4}$ \\ and Hans-Peter Landolt ${ }^{1,3,4}$ \\ Institute of Pharmacology and Toxicology, University of Zürich, 8057 Zürich, Switzerland, ${ }^{2}$ Institute of Medical Molecular Genetics, University of Zürich, \\ CH-8952 Schlieren, Switzerland, ${ }^{3}$ Zürich Center for Integrative Human Physiology, University of Zürich, 8057 Zürich, Switzerland, and ${ }^{4}$ Neuroscience \\ Center Zurich, University of Zürich and ETH Zürich, 8057 Zürich, Switzerland
}

While dopamine affects fundamental brain processes such as movement control, emotional responses, addiction, and pain, the roles for this neurotransmitter in regulating wakefulness and sleep are incompletely understood. Genetically modified animal models with reduced dopamine clearance exhibit hypersensitivity to caffeine, reduced-responsiveness to modafinil, and increased homeostatic response to prolonged wakefulness when compared with wild-type animals. Here we studied sleep-wake regulation in humans and combined pharmacogenetic and neurophysiologic methods to analyze the effects of the 3'-UTR variable-number-tandem-repeat polymorphism of the gene (DAT1, SLC6A3) encoding dopamine transporter (DAT). Previous research demonstrated that healthy homozygous 10 -repeat $(10 \mathrm{R} / 10 \mathrm{R})$ allele carriers of this genetic variant have reduced striatal DAT protein expression when compared with 9-repeat (9R) allele carriers. Objective and subjective estimates of caffeine sensitivity were higher in 10R allele homozygotes than in carriers of the $9 \mathrm{R}$ allele. Moreover, caffeine and modafinil affected wakefulness-induced changes in functional bands (delta, sigma, beta) of rhythmic brain activity in wakefulness and sleep in a DAT1 genotype-dependent manner. Finally, the sleep deprivation-induced increase in well established neurophysiologic markers of sleep homeostasis, including slow-wave sleep, electroencephalographic slowwave activity $(0.5-4.5 \mathrm{~Hz})$, and number of low-frequency $(0.5-2.0 \mathrm{~Hz})$ oscillations in non-rapid-eye-movement sleep, was significantly larger in the $10 \mathrm{R} / 10 \mathrm{R}$ genotype than in the $9 \mathrm{R}$ allele carriers of $D A T 1$. Together, the data suggest that the dopamine transporter contributes to homeostatic sleep-wake regulation in humans.

\section{Introduction}

The concept of sleep homeostasis predicts that increased sleep need after prolonged wakefulness results in compensatory changes in sleep duration and intensity in recovery sleep (Borbély, 1982). Slow-wave sleep (SWS); electroencephalogram (EEG) slow-wave activity (SWA; power within $\sim 0.5-4.5 \mathrm{~Hz}$ ); and number, amplitude, and slope of individual slow $(0.5-2.0 \mathrm{~Hz})$ waves in non-rapideye-movement (NREM) sleep are robust physiological markers of sleep homeostasis (Borbély, 1982; Achermann and Borbély, 2011). The neurochemical and molecular bases underlying this fundamental regulatory mechanism of wakefulness and sleep are poorly understood.

Accumulating evidence suggests the contribution of dopamine to sleep homeostasis. Mutant flies $\left(D a t^{l o}\right)$ with reduced do-

Received Sept. 26, 2013; revised Nov. 21, 2013; accepted Nov. 21, 2013.

Author contributions: H.-P.L. designed research; S.C.H., V.B., and H.-P.L. performed research; W.B., P.A., and H.-P.L. contributed unpublished reagents/analytic tools; S.C.H., A.B., V.B., and H.-P.L. analyzed data; S.C.H. and H.-P.L. wrote the paper.

This work was supported by the Swiss National Science Foundation (Grant 320030-135414), the University Research Priority Program "Integrative Human Physiology" (University of Zürich), and the Clinical Research Priority Program "Sleep \& Health" (University of Zürich). We thank Drs. S. Bodenmann and J. Rétey for data collection and sleep stage scoring, and Dr. T. Rusterholz, A. Valomon, and Dr. R. Dürr for their help with data analyses.

The authors declare no competing financial interests.

Correspondence should be addressed to Dr. Hans-Peter Landolt, Institute of Pharmacology and Toxicology, University of Zürich, Winterthurerstrasse 190, 8057 Zürich, Switzerland. E-mail: landolt@pharma.uzh.ch.

DOI:10.1523/JNEUROSCI.4128-13.2014

Copyright $\odot 2014$ the authors $\quad 0270-6474 / 14 / 340566-08 \$ 15.00 / 0$ pamine acetyltransferase activity exhibit a greater sleep rebound after prolonged wakefulness than wild-type controls (Greenspan et al., 2001). Furthermore, Drosophila and mouse mutants lacking functional dopamine transporters (DAT) exhibit prolonged wakefulness and shortened sleep (Giros et al., 1996; Wisor et al., 2001; Kume et al., 2005; Wu et al., 2008). The DAT is highly expressed in striatum (Lewis et al., 2001), where it is responsible for re-uptake of dopamine (Giros and Caron, 1993) and constitutes the limiting mechanism of dopaminergic neurotransmission (Jones et al., 1998; Benoit-Marand et al., 2000). Dat knock-out mice are hypersensitive to caffeine (Wisor et al., 2001), consistent with the notion that dopaminergic mechanisms importantly contribute to wake-promotion of this stimulant (Boutrel and Koob, 2004; Andretic et al., 2008).

In humans, the roles for dopamine in sleep-wake regulation are not well understood. Patients with Parkinson's disease typically present with disturbed sleep and daytime sleepiness (Park and Stacy, 2011), whereas in healthy volunteers L-dopa and $D_{2} / D_{3}$ receptor agonists may reduce vigilance and increase sleepiness (Andreu et al., 1999; Micallef et al., 2009). Caffeine increases striatal dopamine (Kaasinen et al., 2004). The effects of this xanthine on sleep are modulated by genetic variants of adenosine $\mathrm{A}_{2 \mathrm{~A}}$ receptors (Rétey et al., 2007; Bodenmann et al., 2012). Interestingly, these receptors are also primarily expressed in striatum and functionally interact with $\mathrm{D}_{1} / \mathrm{D}_{2}$ receptors (Lovinger, 2010). 
The wake-promoting agent, modafinil, binds to DAT (Mignot et al., 1994; Volkow et al., 2009) and is ineffective in Dat knockout mice (Wisor et al., 2001). Previous research suggests that this compound does not interfere with sleep homeostasis (Kopp et al., 2002; Bodenmann et al., 2009; Bodenmann and Landolt, 2010). Nevertheless, based on preclinical evidence for a modulatory role of dopamine in sleep homeostasis (Greenspan et al., 2001), we expected that a variable-number-of-tandem-repeat (VNTR) polymorphism (SNP-ID: rs28363170) of the DAT gene (DAT1, SLC6A3) may affect the homeostatic response to sleep loss in healthy adults. Nine or 10 repeats of a $40 \mathrm{bp}$ sequence of this genetic variant are most common (Vandenbergh et al., 1992). Ten-repeat (10R) allele homozygotes have $15-20 \%$ reduced DAT availability in the striatum compared with heterozygous and homozygous 9-repeat (9R) allele carriers (Costa et al., 2011; Spencer et al., 2013). Given the findings in Dat flies and Dat knock-out mice, we hypothesized that neurophysiologic markers of sleep homeostasis are more strongly affected by caffeine and sleep deprivation in 10R/10R homozygotes than in $9 \mathrm{R}$ allele carriers.

\section{Materials and Methods}

Study participants and genotyping. The study protocol was approved by the ethics committee of the Canton of Zürich for research on human subjects. Written informed consent was obtained from all participants before the experiments, as required according to the principles in the Declaration of Helsinki. All subjects received financial compensation for their participation.

A total of 504 healthy volunteers ( 374 males, 130 females) between 18 and 35 years of age were investigated. They were interested in participating in sleep studies and provided $3 \mathrm{ml}$ of fresh EDTA blood $(n=472$; Wizard Genomic DNA Purification Kit; Promega) or saliva ( $n=32$; NucleoSpin Blood Kit, Marchery-Nagel AG) for isolation of genomic DNA. Their genotype of the rs 28363170 polymorphism of DAT1 was determined by allele-specific PCR on an MJ Research PTC-225 thermal cycler (MJ Research/Bio-Rad) at an annealing temperature of $67^{\circ} \mathrm{C}$. Forward primer, 5' -tgtggtgtagggaacggcctga- $3^{\prime}$, and reverse primer, 5'cttcctggaggtcacggctcaa-3', with HOT FIREPol DNA polymerase was used. The $430-480$ bp PCR products were analyzed by agarose gel electrophoresis. All analyses were replicated at least once for independent confirmation. In total, 258 individuals ( 69 females) were 10R/10R allele carriers, 204 ( 56 females) were heterozygous 9R/10R allele carriers, and 23 (4 females) were homozygous 9R/9R allele carriers. Nineteen carriers of rare DAT1 alleles $(3.8 \%)$ were excluded from the analyses. The allele frequencies in our sample were consistent with previous findings in a Caucasian population, yet may differ considerably from other world populations (Mitchell et al., 2000).

To examine a possible impact of the DAT1 polymorphism on sleep-wake regulation, sleep and sleep EEG recordings before and after sleep deprivation were analyzed in a subset of 57 genotyped, right-handed subjects ( 46 men and 11 women) who previously completed sleep studies in our laboratory. Given the low number of 9R/9R homozygotes $(n=3)$, homozygous and heterozygous $(9 \mathrm{R} / 10 \mathrm{R}) 9 \mathrm{R}$ allele carriers $(n=27)$ were grouped and compared with $10 \mathrm{R} / 10 \mathrm{R}$ homozygotes $(n=30)$. Based on previous research, these two groups presumably differ in DAT protein expression (Jacobsen et al., 2000; van Dyck et al., 2005; van de Giessen et al., 2009; Costa et al., 2011; Spencer et al., 2013). They accurately matched in age, body mass index, habitual sleep duration, and daily caffeine and alcohol consumption, as well as in the distribution of distinct COMT and adenosine $\mathrm{A}_{2 \mathrm{~A}}$ receptor (ADORA2A) genotypes (Table 1). Control of these gene variants is important because previous work revealed that they associate with individual differences in neurobehavioral performance during prolonged waking and the behavioral and neurophysiological effects of modafinil and caffeine (Bodenmann and Landolt, 2010; Bodenmann et al., 2012).

All volunteers reported to be good sleepers, adhering to regular bedtimes, to be in good physical health, and to have a medical history
Table 1. Demographics

\begin{tabular}{lccc}
\hline & 10R/10R & 9R allele carriers & $p$ value \\
\hline COMT genotype (rs4680; G/A) & & & 1.00 \\
$\quad$ G/G (Val/Val) & 13 & 11 & \\
G/A (Val/Met) & 8 & 7 & \\
A/A (Met/Met) & 9 & 9 & 0.15 \\
ADORA2A genotype (rs575876; T/C) & & & \\
T/T & 8 & 4 & \\
C/T & 16 & 11 & 1.00 \\
C/C & 6 & 12 & 0.89 \\
Sex ratio (\% females) & 20.0 & 18.5 & 0.09 \\
Age (years) & $24.6 \pm 0.6$ & $24.7 \pm 0.6$ & 0.79 \\
Body mass index (kg/m ${ }^{2}$ ) & $22.8 \pm 0.4$ & $22.0 \pm 0.3$ & 0.31 \\
Habitual sleep duration (hours) & $7.3 \pm 0.2$ & $7.4 \pm 0.2$ & 0.60 \\
Caffeine consumption (mg/d) & $139.0 \pm 26.0$ & $103.6 \pm 22.5$ & \\
Alcohol consumption (drinks/week) & $3.2 \pm 0.6$ & $2.8 \pm 0.4$ & 0.26 \\
Trait Anxiety (STAl) & $39.3 \pm 1.5$ & $36.9 \pm 1.5$ & \\
Daytime Sleepiness (ESS) & $7.2 \pm 0.5$ & $7.0 \pm 0.5$ & 0.81 \\
\hline
\end{tabular}

Symbols of the National Center for Biotechnology Information indicate genes encoding dopamine transporter (DAT1), catechol-0-methyl-transferase (COMT), and adenosine $A_{2 A}$ receptor (ADORA2A). The distributions of COMI and $A D O R A 2 A$ genotypes and the sex ratio in $10 R / 10 R$ and $9 R$ allele carriers of $D A T 1$ did not differ between the two groups (Fisher's Exact Tests). Other variables represent mean \pm SEM, based on validated self-report questionnaires; $p$-values refer to two-tailed Student's $t$ test. STAl, State-trait anxiety inventory (Spielberger et al., 1970); ESS, Epworth Sleepiness Scale (Johns, 1991).

free of neurological and psychiatric disorders. Two months before enrollment, subjects stated not to have consumed any medication or illicit drugs, not to have passed through time zones, and to consume moderate amounts of caffeine and alcohol. To check for potential undiagnosed sleep disorders or low sleep efficiency $(<85 \%)$, they underwent a screening night in the sleep laboratory before study inclusion. Two weeks before study initiation, participants were instructed to wear a wrist activity monitor on their nondominant arm, to fill out a sleep-wake diary, and to completely refrain from intake of caffeine. The final $3 \mathrm{~d}$ before the start of the experiment, they were required to strictly maintain regular bedtimes ( $8 \mathrm{~h}$ sleep) and to abstain from alcohol.

Sleep deprivation protocol. The sleep deprivation study involved either one ( $n=19 ; 12$ females, 7 males) or two ( $n=38$; all males) experimental blocks. Three participants completing only one block were moderate smokers ( $<10$ cigarettes per day). Each experimental block consisted of three nocturnal sleep recordings, all starting either at 23:00 or 00:00, divided into $8 \mathrm{~h}$ adaptation and baseline nights, $40 \mathrm{~h}$ of constantly supervised prolonged wakefulness, and concluded by a 10 h recovery night.

Subjects completing two experimental blocks were administered after 11 (at 19:00) and $23 \mathrm{~h} \mathrm{(at} \mathrm{07:00)} \mathrm{of} \mathrm{prolonged} \mathrm{wakefulness} 2 \times 200 \mathrm{mg}$ of caffeine and placebo $(n=16 ; 10 \mathrm{R} / 10 \mathrm{R}: n=9 ; 9 \mathrm{R} / 10 \mathrm{R}: n=7)$, or $2 \times 100$ mg of modafinil and placebo $(n=22 ; 10 \mathrm{R} / 10 \mathrm{R}: n=11 ; 9 \mathrm{R} / 10 \mathrm{R}: n=8$, 9R/9R: $n=3$ ), in randomized, double-blind cross-over fashion.

All-night polysomnography. Sleep was polysomnographically quantified during all experimental nights. The EEG, electro-oculogram, submental electromyogram, and electrocardiogram were recorded using polygraphic amplifiers (PSA24; Braintronics; Rétey et al., 2006) or Artisan, Micromed (Bachmann et al., 2012) as follows. For 16 subjects recorded via PSA24 amplifiers, analog EEG data were bandpass filtered $(-3 \mathrm{~dB}$ at $0.16 \mathrm{~Hz} ;-3 \mathrm{~dB}$ at $102 \mathrm{~Hz})$ and sampled at $512 \mathrm{~Hz}$, then digitally low-pass filtered $(-3 \mathrm{~dB}$ at $49 \mathrm{~Hz})$ and stored with a resolution of $128 \mathrm{~Hz}$. For 41 subjects recorded via Artisan amplifiers, analog EEG data were bandpass filtered $(-3 \mathrm{~dB}$ at $0.15 \mathrm{~Hz} ;-3 \mathrm{~dB}$ at $67.2 \mathrm{~Hz})$, sampled, and stored with a resolution of $256 \mathrm{~Hz}$. The EEG data of derivation C3A2 were analyzed.

Sleep stages were visually scored in $20 \mathrm{~s}$ epochs according to standard criteria (Rechtschaffen and Kales, 1968). Four second EEG spectra (fast Fourier transform routine, Hanning window, $0.25 \mathrm{~Hz}$ resolution) were calculated using MATLAB (MathWorks), averaged over five consecutive $4 \mathrm{~s}$ epochs, and matched with scored sleep stages. Arousal- and movement-related artifacts were semi-automatically identified and excluded. All-night power spectra between 0 and $20 \mathrm{~Hz}$ represent the aver- 

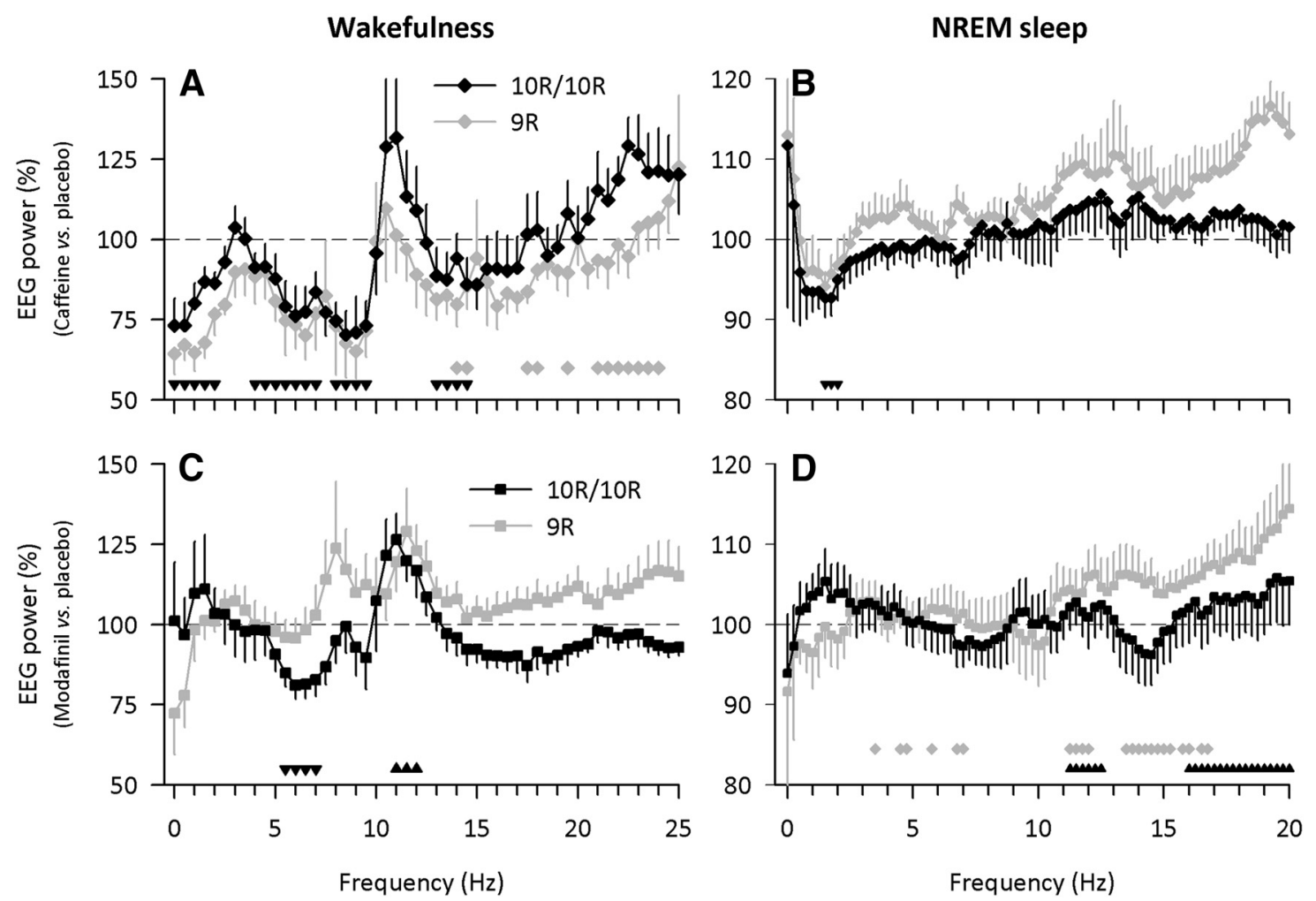

Figure 1. DAT1 genotype modulates the effects of caffeine (10R/10R: $n=9$ [black diamonds]; 9 R allele carriers: $n=7$ [gray diamonds]), and modafinil (10R/10R: $n=11[$ black squares]; $9 R$ allele carriers: $n=11$ [gray squares]) intake during sleep deprivation on EEG activity in wakefulness (eyes open) and NREM sleep. $\boldsymbol{A}, \boldsymbol{B}$, Effects of caffeine. $\boldsymbol{C}, \boldsymbol{D}$, Effects of modafinil. Left, Relative power values in the waking EEG recording sessions at 08:00, 11:00, 14:00, and 17:00 on day 2 of prolonged wakefulness after caffeine $(2 \times 200 \mathrm{mg})$ and modafinil $(2 \times 100 \mathrm{mg})$ were expressed as a percentage of the corresponding values after placebo (horizontal dashed lines at 100\%). Caffeine reduced power in many bins $<14.5 \mathrm{~Hz}$, and increased power in high-beta (21-24 Hz) frequencies (in 10R/10R carriers only). Modafinil reduced theta (5.5-7 Hz) activity and increased alpha (11-12 Hz) activity. Right, Standardized all-night power values in NREM sleep (stages 1-4) after caffeine $(2 \times 200 \mathrm{mg})$ and modafinil $(2 \times 100 \mathrm{mg})$ intake were expressed as a percentage of the corresponding values after placebo (horizontal dashed lines at $100 \%)$. Caffeine reduced $1.5-2$ $\mathrm{Hz}$ activity. Modafinil increased power in many bins in the alpha/beta range $(11.25-20 \mathrm{~Hz}$ ), primarily in $9 \mathrm{R}$ carriers of DAT1. Mean $\pm \mathrm{SEM}$ consecutive $0.5 \mathrm{~Hz}$ (wakefulness) or $0.25 \mathrm{~Hz}$ ( $\mathrm{NREM}$ sleep) frequency bins are plotted. Gray diamonds indicate a significant genotype $\times$ treatment interaction $\left(p_{\text {all }}<0.05\right)$ of a two-way mixed-model ANOVA with the between-subjects factor genotype and the within-subjects factor treatment (caffeine or modafinil). Upward and downward black triangles indicate a significant main effect of treatment $\left(p_{\text {all }}<0.05\right)$. Note the different scales of $y$ - and $x$-axes in wakefulness and NREM sleep.

age of all artifact-free $20 \mathrm{~s}$ values in NREM sleep (stages 1-4). In the recovery nights, data analysis was restricted to the first $8 \mathrm{~h}$ of the $10 \mathrm{~h}$ sleep recordings. All-night and episodic EEG power values in NREM sleep were standardized in each individual to the corresponding all-night power of the baseline night.

To analyze the effects of caffeine, modafinil, DAT1 genotype, and sleep deprivation on individual EEG slow waves, an algorithm previously described (Bersagliere and Achermann, 2010) was applied. Data sampled with $256 \mathrm{~Hz}$ were downsampled to $128 \mathrm{~Hz}$ using the MATLAB function decimate (MathWorks). To ensure reliable wave detection, the EEG $(0.5-2.0 \mathrm{~Hz})$ was bandpass filtered (third-order Chebyshev type II highpass filter; $-3 \mathrm{~dB}$ at $0.4 \mathrm{~Hz}$; sixth-order Chebyshev type II low-pass filter, $-3 \mathrm{~dB}$ at $2.3 \mathrm{~Hz}$ ). Filters were applied both in forward and reverse directions, to prevent phase distortion. Individual positive and negative halfwaves with an amplitude of $\geq 37.5 \mu \mathrm{V}$ (75 $\mu \mathrm{V}$ peak to peak; Rechtschaffen and Kales, 1968) were defined as positive or negative deflections between consecutive zero-line crossings. Waves were analyzed in steps of $0.1 \mathrm{~Hz}$. The amplitude was defined as the local maximum or minimum between two consecutive zero-line crossings, whereas the slope was defined as the amplitude of the peak or the trough, divided by the time from the previous zero-line crossing (initial mean slope). The number of waves included all detected waves that fulfilled the $\geq 37.5$ $\mu \mathrm{V}$-amplitude criterion.

Waking EEG recordings. At $3 \mathrm{~h}$ intervals during the $40 \mathrm{~h}$ prolonged wakefulness, standardized waking EEG recordings were performed. At least $1 \mathrm{~h}$ before each recording, subjects had to stay in the laboratory (constant temperature: $19-21^{\circ} \mathrm{C}$; light intensity: $<150$ lux). Fifteen minutes before each recording, they calmly stayed on their own in their bedrooms. The study participants were instructed to comfortably relax in a chair, and to place their chin on an individually adjusted chinrest. An initial $3 \mathrm{~min}$ recording period with eyes closed was followed by a $5 \mathrm{~min}$ period with eyes open, while subjects fixated a black dot attached to the wall. Artifacts in all derivations were visually identified and excluded. Power spectra (C3A2 derivation) of artifact-free, $2 \mathrm{~s}$ epochs ( $50 \%$ overlap, Hanning window, frequency resolution $0.5 \mathrm{~Hz}$ ) were computed and analyzed between 0 and $25 \mathrm{~Hz}$. To minimize interindividual differences in absolute power and to compensate for circadian effects, spectra were standardized in each individual to the mean of the first four sessions during extended waking.

Statistical analyses. All statistical analyses were performed with SAS 9.1.3 software (SAS Institute). In 10R/10R and 9R allele carriers of DAT1, the effects of caffeine and modafinil on waking EEG, sleep architecture, EEG spectra, and individual EEG slow half-waves, as well as the sleep deprivation-induced rebound in these variables were analyzed. Two- and three-way mixed-model ANOVA for repeated measures (PROC MIXED) with the between-subjects factor "genotype" (10R/10R vs 9R allele carriers) and the within-subjects factors "treatment" (caffeine/ modafinil vs placebo), "NREM sleep episode" (1-4), "condition" (baseline vs sleep deprivation/recovery), and "frequency bin" ( $0.5,0.25$, or 0.1 $\mathrm{Hz}$ resolution) were performed. The significance level was set at $\alpha<0.05$. Only significant effects and interactions are mentioned, unless otherwise specified. Post hoc analyses were only performed when the respective main effect and/or interaction of the ANOVA were significant. 

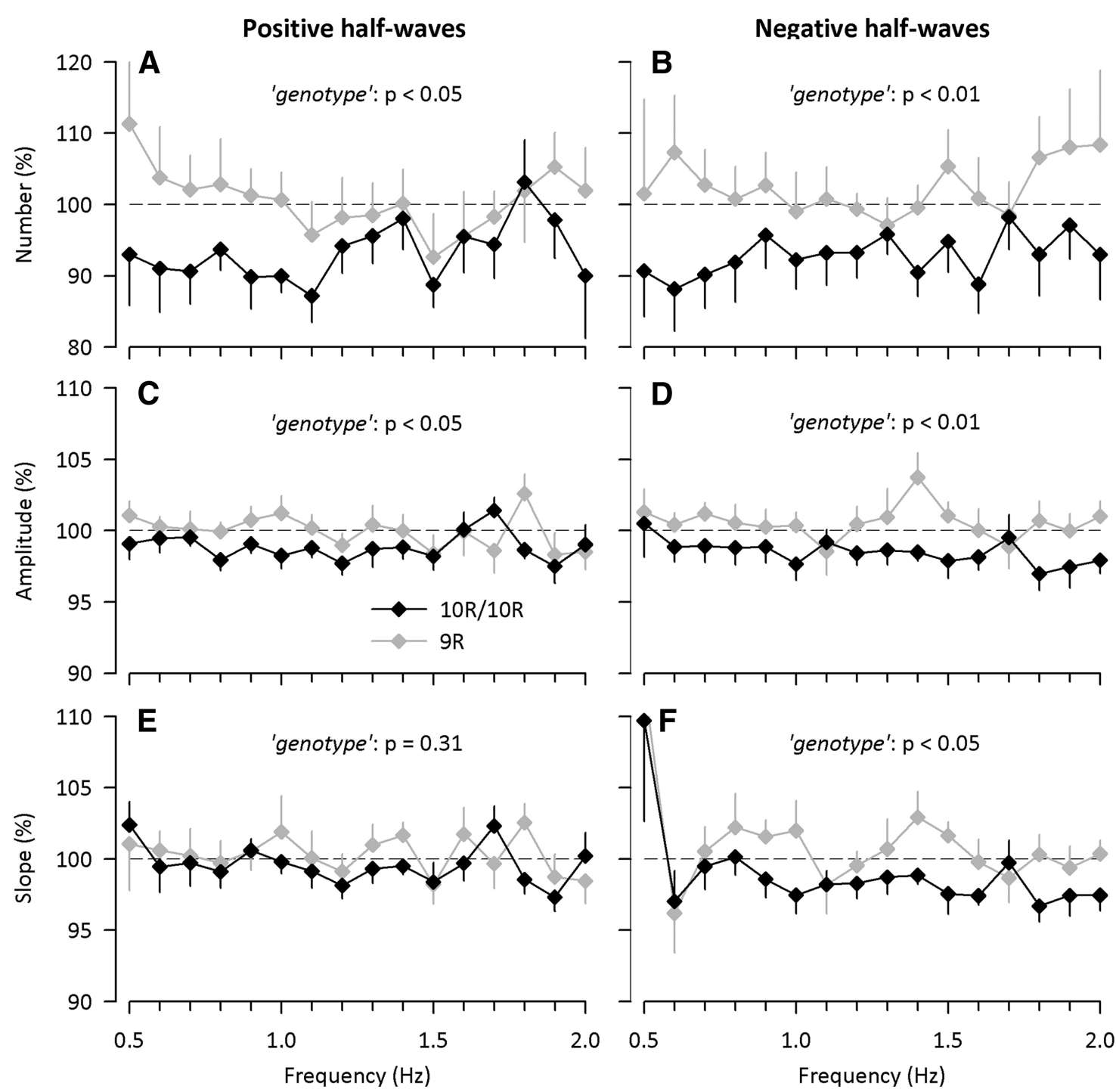

Figure 2. DAT1 genotype modulates the effects of caffeine intake during sleep deprivation on positive (left) and negative (right) EEG slow half-waves in NREM sleep. Number $(\boldsymbol{A}, \boldsymbol{B})$, amplitude $(\boldsymbol{C}, \boldsymbol{D})$, and slope $(\boldsymbol{E}, \boldsymbol{F})$ in 10R/10R (black diamonds, $n=9$ ) and 9R allele carrier (gray diamonds, $n=7$ ) genotypes of DAT1 are illustrated. Absolute data were normalized to the corresponding recovery night after intake of placebo (horizontal dashed line at 100\%) and used for analyses; $p$ values refer to the factor genotype of a two-way, mixed-model ANOVA with the between-subject factor genotype and the within-subject factor frequency bin. Error bars indicate \pm SEM.

\section{Results}

DAT1 genotype modulates effects of caffeine on lowfrequency brain oscillations in wakefulness and sleep To investigate a possible role for DAT in sleep-wake regulation, the combined effects of sleep deprivation and caffeine and modafinil were examined in a dataset of 57 healthy adult $10 \mathrm{R} / 10 \mathrm{R}$ and $9 \mathrm{R}$ allele carriers (Table 1). Sleep architecture in baseline, and the behavioral effects of prolonged wakefulness (i.e., increased sleepiness and impaired performance on the psychomotor vigilance task) were highly similar in the two genotypes (data not shown).

Caffeine intake during sleep deprivation affected EEG lowfrequency activity in wakefulness and sleep. The stimulant reduced waking EEG activity in delta $(<2 \mathrm{~Hz})$, theta $(4-7 \mathrm{~Hz})$, alpha $(8-9.5$ $\mathrm{Hz})$, and low-beta $(13-14.5 \mathrm{~Hz})$ frequencies (treatment: $F_{(1,14)} \geq$ $4.61 ; p_{\text {all }}<0.05$; Fig. $\left.1 A\right)$. Moreover, it enhanced beta $(21-24 \mathrm{~Hz}$; genotype $\times$ treatment interaction: $\left.F_{(1,14)} \geq 4.25 ; p_{\text {all }}<0.05\right)$ activity in $10 \mathrm{R} / 10 \mathrm{R}$ carriers (caffeine: $151.6 \pm 9.5 \%$; placebo: $109.3 \pm 9.7 \%$; $t_{(8)}=-2.40, p<0.05$; two-tailed, paired $t$ test), yet not in $9 \mathrm{R}$ carriers (caffeine: $103.9 \pm 11.4 \%$; placebo: $127.2 \pm 4.5 \%$; $t_{(6)}=1.51, p>$
0.18 ; two-tailed, paired $t$ test). This difference may reflect the higher subjective caffeine sensitivity in 10R allele carriers when compared with 9R allele carriers of $D A T 1$. The proportion of sensitive individuals among all genotyped individuals $(n=485)$ as assessed with the question "Do you consider yourself as caffeine sensitive?" (yes/no) differed among the genotypes ( $p<0.008$, Fisher's exact test). It equaled $38.8 \%(100 / 258)$ in $10 \mathrm{R} / 10 \mathrm{R}$ allele carriers, $33.3 \%(68 / 204)$ in $9 \mathrm{R} / 10 \mathrm{R}$ allele carriers, and $8.7 \%(2 / 23)$ in $9 \mathrm{R} / 9 \mathrm{R}$ allele carriers (online supporting supplemental information, Fig. S1).

During recovery sleep, caffeine consistently reduced EEG lowdelta $(1.5-2.0 \mathrm{~Hz})$ activity in NREM sleep (Fig. 1B). Close inspection of the data indicated that this effect of caffeine may differ between 10R/10R and 9R allele carriers of DAT1. To further examine this notion, individual sleep slow waves were analyzed.

\section{DAT1 genotype modulates the effects of caffeine on} individual slow waves in NREM sleep

Sleep deprivation markedly increased number, amplitude, and slope of individual, positive and negative slow half-waves in re- 
covery sleep when compared with baseline sleep (condition: $\left.F_{(1,55)}>93.7 ; p_{\text {all }}<0.0001\right)$. Intake of caffeine during prolonged wakefulness reduced all these features of negative half-waves, as well as number and amplitude of positive half-waves in 10R/10R carriers of DAT1 (Fig. 2). In contrast, the stimulant did not affect the characteristics of positive and negative slow half-waves in $9 \mathrm{R}$ allele carriers.

\section{Modafinil does not affect low-frequency brain oscillations in wakefulness and sleep}

Intake of modafinil during prolonged wakefulness reduced waking EEG activity in the 5.5-7 Hz range and elevated activity in the $11-12 \mathrm{~Hz}$ band when compared with placebo (treatment: $F_{(1,20)}$ $\geq 5.13$; $p_{\text {all }}<0.05$; Fig. $1 C$ ). In the recovery night, modafinil did not affect low-frequency EEG activity in NREM sleep (Fig. 1D), or the number, amplitude, and slope of EEG slow half-waves (data not shown). Nevertheless, the stimulant increased power in alpha $(11.25-12.5 \mathrm{~Hz})$ and beta $(13.5-20 \mathrm{~Hz})$ frequencies in NREM sleep, primarily in 9R carriers of DAT1 (genotype $\times$ treatment: $F_{(1,20)} \geq 4.49$; $p_{\text {all }}<0.05$; Fig. $\left.1 D\right)$.

\section{DAT1 genotype modulates the rebound in SWS and EEG SWA after sleep deprivation}

Research in animals and humans demonstrated that caffeine attenuates EEG markers of sleep homeostasis after prolonged wakefulness (Schwierin et al., 1996; Landolt et al., 2004; Rétey et al., 2006; Landolt, 2008). Because the effects of caffeine in NREM sleep reflected genotype-dependent changes in EEG slow oscillations, the repercussions of prolonged wakefulness on these neurophysiologic markers of sleep homeostasis were examined in $10 \mathrm{R} / 10 \mathrm{R}$ and $9 \mathrm{R}$ allele carriers of DAT1. In both genotypes, sleep deprivation increased sleep efficiency and the duration of NREM sleep, and shortened sleep latency, sleep stages 1 and 2, REM sleep, and wakefulness after sleep onset in the recovery night when compared with the baseline night (online supporting supplemental information, Table S1). Nevertheless, the rebound in deep SWS was strikingly different between $10 \mathrm{R} / 10 \mathrm{R}$ and $9 \mathrm{R}$ allele carriers of DAT1 (condition $\times$ genotype interaction: $F_{(1,55)}=$ 10.8, $p<0.002$; condition: $\left.F_{(1,55)}=644.1, p<0.0001\right)$. More specifically, it was $\sim 15$ min longer in $10 \mathrm{R} / 10 \mathrm{R}$ than in $9 \mathrm{R}$ allele carriers $\left(t_{(55)}=-3.32, p<0.002\right.$; two-tailed t test; Fig. 3, inset). This difference was accompanied by a slightly more pronounced reduction in stage 2 sleep in the 10R/10R genotype $(-21.6 \pm 4.8$ $\mathrm{min})$ than in the $9 \mathrm{R}$ allele carriers $(-9.8 \pm 4.8 \mathrm{~min}$; genotype $X$ condition: $\left.F_{(1,55)}=3.0, p=0.09\right)$.

In baseline and recovery nights, EEG SWA (0.5-4.5 Hz range) decayed exponentially across consecutive NREM sleep episodes, reflecting the dissipation of homeostatically regulated NREM sleep pressure. The time constants of the decay $\left(\tau_{d}\right)$ quantified by the method proposed by Rusterholz et al. (2010) were similar in both nights and genotypes (online supporting supplemental information, Fig. S2). Interestingly, however, the rebound in SWA in the recovery night compared with the baseline night was larger in $10 \mathrm{R} / 10 \mathrm{R}$ than in $9 \mathrm{R}$ allele carriers of DAT1 (genotype: $F_{(1,55)}=$ $4.8, p=0.03$; NREM sleep episode: $F_{(3,165)}=372.7, p<0.0001$; Fig. 3). The analyses of individual EEG slow waves revealed that this difference reflected a more pronounced increase in $10 \mathrm{R} / 10 \mathrm{R}$ than in $9 \mathrm{R}$ allele genotypes in the number of positive and negative half-waves after sleep deprivation (Fig. 4). In contrast, the changes in amplitudes and slopes of individual slow waves in NREM sleep did not differ between the genotypes.

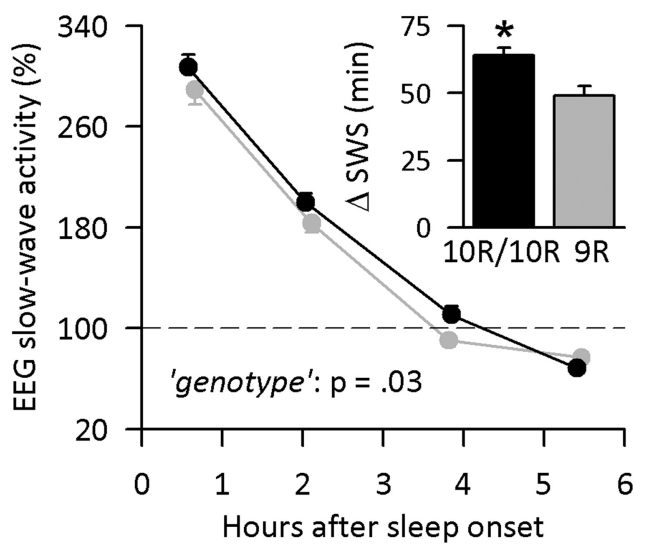

Figure 3. DAT1 genotype modulates the rebound in SWS and EEG SWA $(0.5-4.5 \mathrm{~Hz})$ in the recovery night after sleep deprivation. Inset, Data reflect the mean absolute all-night increase in SWS after sleep deprivation when compared with baseline, in 10R/10R (black bar, $n=30$ ) and 9 R allele carrier (gray bar, $n=27$ ) genotypes of DAT1. ${ }^{*} p<0.002$ (two-tailed $t$ test). Main figure, Mean relative SWA, expressed as a percentage of the all-night value in baseline (horizontal dashed line at 100\%). Values in 10R/10R (black dots, $n=30$ ) and $9 \mathrm{R}$ allele carriers (gray dots, $n=27$ ) across the first four NREM sleep episodes were plotted at the mean episode midpoints relative to sleep onset. Error bars indicate \pm SEM.

\section{Discussion}

Ample evidence suggests that homozygous 10R/10R allele carriers of the 3 '-VNTR polymorphism of the DAT1 gene have reduced DAT protein expression in the striatum when compared with 9R allele carriers (Heinz et al., 2000; Jacobsen et al., 2000; Fuke et al., 2001; VanNess et al., 2005; van Dyck et al., 2005; van de Giessen et al., 2009; Costa et al., 2011; Spencer et al., 2013). Based on preclinical studies in mutant animals (Giros et al., 1996; Greenspan et al., 2001; Wisor et al., 2001; Kume et al., 2005; Andretic et al., 2008; Wu et al., 2008) as well as molecular brain imaging data in humans (Volkow et al., 2012), we hypothesized that this "experiment of nature" is associated with individual differences in sleep-wake regulation. Our data revealed not only pharmacogenetic support for this hypothesis, but also demonstrated that healthy carriers of the $10 \mathrm{R} / 10 \mathrm{R}$ genotype show increased rebound in SWS, SWA, and number of slow EEG waves after sleep deprivation when compared with 9R allele carriers. These findings suggest an increased homeostatic response to sleep deprivation in $10 \mathrm{R} / 10 \mathrm{R}$ homozygotes when compared with 9R allele carriers of DAT1.

Apart from being an adenosine receptor antagonist (Fredholm et al., 1999), the stimulant action of caffeine has been suggested to also rely on the dopaminergic system, and to depend on DAT expression (Wisor et al., 2001; Boutrel and Koob, 2004; Fisone et al., 2004; Andretic et al., 2008). Our study showed that caffeine administered during sleep deprivation increased EEG 21-24 Hz activity in wakefulness in 10R/10 R homozygotes, yet not in $9 \mathrm{R}$ allele carriers (Fig. $1 A$ ). Elevated EEG $\beta$-activity in waking was also reported after oral intake of the DAT blocker, cocaine, which may reflect increased brain arousal (Herning et al., 1985). Together with observations in mice (Wisor et al., 2001), the data suggest that reduced expression of DAT, such as in $10 \mathrm{R} / 10 \mathrm{R}$ allele carriers of DAT1 and in Dat knock-out animals, is associated with elevated sensitivity to the stimulant action of the adenosine receptor antagonist caffeine.

The present study revealed that this conclusion may also apply to the effects of caffeine on neurophysiologic markers of sleep homeostasis. Intake of the stimulant during prolonged wakefulness reduced EEG low-frequency activity in the delta (wakeful- 


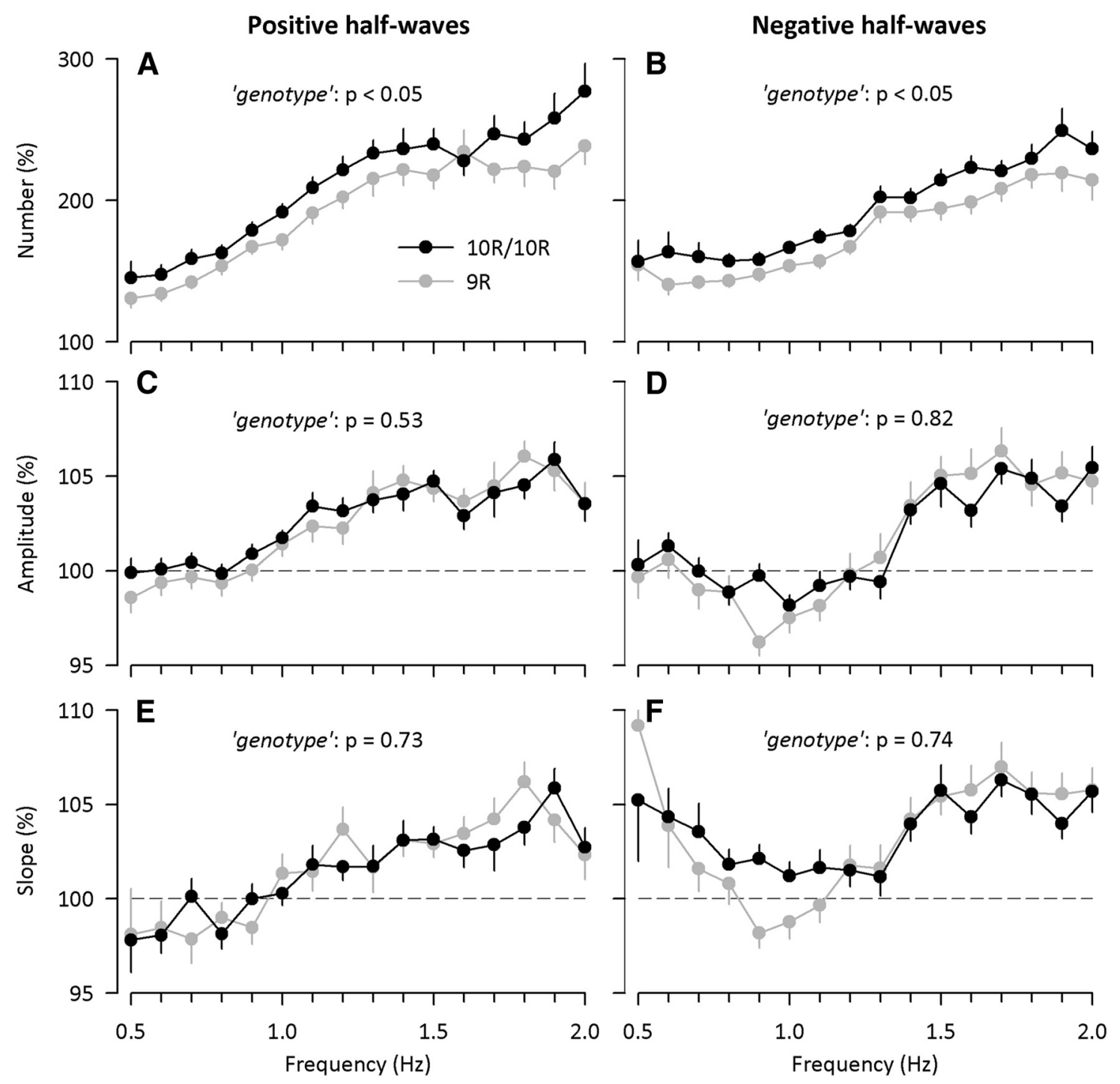

Figure 4. DAT1 genotype modulates the effects of sleep deprivation on positive (left) and negative (right) EEG slow half-waves in NREM sleep. Number $(\boldsymbol{A}, \boldsymbol{B})$, amplitude $(\boldsymbol{C}, \boldsymbol{D})$, and slope $(\boldsymbol{E}, \boldsymbol{F})$ in 10R/10R (black dots, $n=30$ ) and 9 R allele carrier (gray dots, $n=27$ ) genotypes of DAT1 are illustrated. Normalized data relative to the corresponding all-night baseline values (= 100\%) were analyzed; $p$ values refer to the factor genotype of a two-way, mixed-model ANOVA with the between-subject factor genotype and the within-subject factor frequency bin. Error bars indicate \pm SEM.

ness: 0-2 Hz; NREM sleep: 1.5-2 Hz) and theta (wakefulness: $4-9.5 \mathrm{~Hz}$ ) ranges in vigilance state-specific manner (Fig. 1A,B). In contrast, administration of modafinil, which reduces DATmediated re-uptake of dopamine in animals (Mignot et al., 1994) and humans (Volkow et al., 2009), decreased theta power (5.5-7 $\mathrm{Hz}$ ) in waking, yet did not affect delta activity in NREM sleep (Fig. 1C,D). These findings corroborate the previous conclusion that intake of caffeine and modafinil during sleep deprivation differentially affects EEG markers of sleep homeostasis in wakefulness and sleep (Bodenmann et al., 2009; Bodenmann and Landolt, 2010). The present refined analyses revealed that caffeine reduced number, amplitude, and slope of sleep slow waves in a $D A T 1$ genotype-dependent manner. This finding suggests that the interference of caffeine with neurophysiologic markers of sleep homeostasis not only relies on adenosinergic mechanisms but also involves dopaminergic processes. Furthermore, adenosinergic-dopaminergic interactions appear necessary for the stimulant-induced suppression of low-frequency brain oscillations reflecting sleep homeostasis. Supporting this notion, genetic variation of $A D O R A 2 A$ also modulates the effects of caffeine on SWA after sleep deprivation (Bodenmann et al., 2012).
A modulatory role for dopamine in the homeostatic response to sleep deprivation was previously observed in fruit flies carrying the Dat ${ }^{\text {lo }}$ mutation (Greenspan et al., 2001). This mutation results in pronounced reduction in enzymatic clearance of dopamine (Greenspan et al., 2001). Both mutant and control flies slept similarly in baseline. Following $12 \mathrm{~h}$ of sleep deprivation, however, mutant flies displayed a greater sleep rebound than controls, and the homeostatic response was even larger in $D a t^{l o} / D f$ flies who exhibit a complete removal of the gene encoding dopamine acetyltransferase (Greenspan et al., 2001). In accordance with these studies in flies, we and others (Guindalini et al., 2010) investigating healthy humans found no impact of the DAT1 VNTR on sleep architecture in baseline. Nevertheless, a challenge of sleep homeostasis by sleep deprivation induced a larger rebound in SWS, SWA, and the number of individual slow half-waves in NREM sleep in 10R/10R allele homozygotes than in 9R allele carriers. Thus, our fine-grained EEG analyses indicate for the first time in humans that DAT contributes to homeostatic sleep-wake regulation.

Individual low-frequency EEG oscillations in the $0.5-2 \mathrm{~Hz}$ range in NREM sleep are homeostatically regulated (Bersagliere 
and Achermann, 2010; online supporting supplemental information, Fig. S3). They are thought to reflect, at the cellular level, the degree of synchrony in the occurrence of up- and down-states in the membrane potential of cortical neurons (Mukovski et al., 2007; Vyazovskiy et al., 2009). Sleep loss increased in a genotypedependent manner the number of slow waves, but not their amplitude and slope (Fig. 4). Together with the data presented in Figure 3 , this observation suggests that DAT1 modulates the duration of the sleep deprivation-induced rebound in SWS, rather than the absolute level of SWA that reflects the synchrony of upand down-states in cortical networks. A possible underlying mechanism may be related to retinoic acid receptors, which affect dopamine signaling in the mesolimbic system (Krezel et al., 1998) and strongly contribute to EEG slow-wave oscillations during sleep in mice (Maret et al., 2005).

Not only preclinical data, but also clinical observations, support a role for striatal dopamine in sleep-wake regulation. Pronounced hyperactivity, caffeine hypersensitivity, and reduced sleep are typically observed in Dat knock-out animals (Giros et al., 1996; Wisor et al., 2001; Kume et al., 2005; Wu et al., 2008). In contrast, impaired dopaminergic neurotransmission in the striatum in patients with Parkinson's disease is often accompanied by severely disturbed sleep and disabling daytime sleepiness (Park and Stacy, 2011). It is evident that our findings in healthy individuals with distinct DAT1 genotypes need to be treated with caution when compared with sleep-wake changes in Dat knockout animals and in patients with neurodegenerative depletion of dopamine. Nevertheless, the stronger response to caffeine and the larger rebound in neurophysiologic markers of sleep homeostasis after sleep deprivation are consistent with reduced DAT expression and increased dopaminergic signaling in 10R/10R homozygotes than in $9 \mathrm{R}$ allele carriers. Thus, our study provides novel physiological evidence for a functional effect of the common VNTR polymorphism of DAT1. Moreover, because the DAT protein is primarily expressed in the striatum, it suggests a specific role for striatal dopaminergic neurotransmission in sleep homeostasis.

\section{Notes}

Supplemental material for this article is available at http://www.pharma. uzh.ch/research/chronobiology/areas/psychopharmacology/DAT1_sleep_ homeostasis.pdf. The online supporting supplemental material (one table and three figures) includes more detailed information on DAT1 genotypedependent subjective caffeine sensitivity, sleep architecture, analysis of the individual positive and negative slow half-waves for absolute data, and for the estimates of SWA decay time constants. This material has not been peer reviewed.

\section{References}

Achermann P, Borbély AA (2011) Sleep homeostasis and models of sleep regulation. In: Principles and practice of sleep medicine, Ed 5 (Kryger MH, Roth T, Dement WC, eds), pp 431-444. St. Louis: Saunders.

Andretic R, Kim YC, Jones FS, Han KA, Greenspan RJ (2008) Drosophila D1 dopamine receptor mediates caffeine-induced arousal. Proc Natl Acad Sci U S A 105:20392-20397. CrossRef Medline

Andreu N, Chalé JJ, Senard JM, Thalamas C, Montastruc JL, Rascol O (1999) L-dopa-induced sedation: a double-blind cross-over controlled study versus triazolam and placebo in healthy volunteers. Clin Neuropharmacol 22:15-23. CrossRef Medline

Bachmann V, Klaus F, Bodenmann S, Schäfer N, Brugger P, Huber S, Berger W, Landolt HP (2012) Functional ADA polymorphism increases sleep depth and reduces vigilant attention in humans. Cereb Cortex 22:962970. CrossRef Medline

Benoit-Marand M, Jaber M, Gonon F (2000) Release and elimination of dopamine in vivo in mice lacking the dopamine transporter: functional consequences. Eur J Neurosci 12:2985-2992. CrossRef Medline
Bersagliere A, Achermann P (2010) Slow oscillations in human non-rapid eye movement sleep electroencephalogram: effects of increased sleep pressure. J Sleep Res 19:228-237. CrossRef Medline

Bodenmann S, Landolt HP (2010) Effects of modafinil on the sleep EEG depend on Val158Met genotype of COMT. Sleep 33:1027-1035. Medline

Bodenmann S, Rusterholz T, Dürr R, Stoll C, Bachmann V, Geissler E, JaggiSchwarz K, Landolt HP (2009) The functional Val158Met polymorphism of COMT predicts interindividual differences in brain alpha oscillations in young men. J Neurosci 29:10855-10862. CrossRef Medline

Bodenmann S, Hohoff C, Freitag C, Deckert J, Rétey JV, Bachmann V, Landolt HP (2012) Polymorphisms of ADORA2A modulate psychomotor vigilance and the effects of caffeine on neurohevavioural performance and sleep EEG after sleep deprivation. Br J Pharmacol 165:1904-1913. CrossRef Medline

Borbély AA (1982) A two process model of sleep regulation. Hum Neurobiol 1:195-204. Medline

Boutrel B, Koob GF (2004) What keeps us awake: the neuropharmacology of stimulants and wakefulness-promoting medications. Sleep 27:11811194. Medline

Costa A, Riedel M, Müller U, Möller HJ, Ettinger U (2011) Relationship between SLC6A3 genotype and striatal dopamine transporter availability: a meta-analysis of human single photon emission computed tomography studies. Synapse 65:998-1005. CrossRef Medline

Fisone G, Borgkvist A, Usiello A (2004) Caffeine as a psychomotor stimulant: mechanism of action. Cell Mol Life Sci 61:857-872. CrossRef Medline

Fredholm BB, Bättig K, Holmén J, Nehlig A, Zvartau EE (1999) Actions of caffeine in the brain with special reference to factors that contribute to its widespread use. Pharmacol Rev 51:83-133. Medline

Fuke S, Suo S, Takahashi N, Koike H, Sasagawa N, Ishiura S (2001) The VNTR polymorphism of the human dopamine transporter (DAT1) gene affects gene expression. Pharmacogenomics J 1:152-156. CrossRef Medline

Giros B, Caron MG (1993) Molecular characterization of the dopamine transporter. Trends Pharmacol Sci 14:43-49. CrossRef Medline

Giros B, Jaber M, Jones SR, Wightman RM, Caron MG (1996) Hyperlocomotion and indifference to cocaine and amphetamine in mice lacking the dopamine transporter. Nature 379:606-612. CrossRef Medline

Greenspan RJ, Tononi G, Cirelli C, Shaw PJ (2001) Sleep and the fruit fly. Trends Neurosci 24:142-145. CrossRef Medline

Guindalini C, Martins RC, Andersen ML, Tufik S (2010) Influence of genotype on dopamine transporter availability in human striatum and sleep architecture. Psychiatry Res 179:238-240. CrossRef Medline

Heinz A, Goldman D, Jones DW, Palmour R, Hommer D, Gorey JG, Lee KS, Linnoila M, Weinberger DR (2000) Genotype influences in vivo dopamine transporter availability in human striatum. Neuropsychopharmacology 22:133-139. CrossRef Medline

Herning RI, Jones RT, Hooker WD, Mendelson J, Blackwell L (1985) Cocaine increases EEG beta: a replication and extension of Hans Berger's historic experiments. Electroencephalogr Clin Neurophysiol 60:470477. CrossRef Medline

Jacobsen LK, Staley JK, Zoghbi SS, Seibyl JP, Kosten TR, Innis RB, Gelernter J (2000) Prediction of dopamine transporter binding availability by genotype: a preliminary report. Am J Psychiatry 157:1700-1703. CrossRef Medline

Johns MW (1991) A new method for measuring daytime sleepiness: the Epworth sleepiness scale. Sleep 14:540-545. Medline

Jones SR, Gainetdinov RR, Jaber M, Giros B, Wightman RM, Caron MG (1998) Profound neuronal plasticity in response to inactivation of the dopamine transporter. Proc Natl Acad Sci U S A 95:4029-4034. CrossRef Medline

Kaasinen V, Aalto S, Någren K, Rinne JO (2004) Dopaminergic effects of caffeine in the human striatum and thalamus. Neuroreport 15:281-285. CrossRef Medline

Kopp C, Petit JM, Magistretti P, Borbély AA, Tobler I (2002) Comparison of the effects of modafinil and sleep deprivation on sleep and cortical EEG spectra in mice. Neuropharmacology 43:110-118. CrossRef Medline

Krezel W, Ghyselinck N, Samad TA, Dupé V, Kastner P, Borrelli E, Chambon $P$ (1998) Impaired locomotion and dopamine signaling in retinoid receptor mutant mice. Science 279:863-867. CrossRef Medline

Kume K, Kume S, Park SK, Hirsh J, Jackson FR (2005) Dopamine is a reg- 
ulator of arousal in the fruit fly. J Neurosci 25:7377-7384. CrossRef Medline

Landolt HP (2008) Sleep homeostasis: a role for adenosine in humans? Biochem Pharmacol 75:2070-2079. CrossRef Medline

Landolt HP, Rétey JV, Tönz K, Gottselig JM, Khatami R, Buckelmüller I, Achermann P (2004) Caffeine attenuates waking and sleep electroencephalographic markers of sleep homeostasis in humans. Neuropsychopharmacology 29:1933-1939. CrossRef Medline

Lewis DA, Melchitzky DS, Sesack SR, Whitehead RE, Auh S, Sampson A (2001) Dopamine transporter immunoreactivity in monkey cerebral cortex: regional, laminar, and ultrastructural localization. J Comp Neurol 432:119-136. CrossRef Medline

Lovinger DM (2010) Neurotransmitter roles in synaptic modulation, plasticity and learning in the dorsal striatum. Neuropharmacology 58:951961. CrossRef Medline

Maret S, Franken P, Dauvilliers Y, Ghyselinck NB, Chambon P, Tafti M (2005) Retinoic acid signaling affects cortical synchrony during sleep. Science 310:111-113. CrossRef Medline

Micallef J, Rey M, Eusebio A, Audebert C, Rouby F, Jouve E, Tardieu S, Blin O (2009) Antiparkinsonian drug-induced sleepiness: a double-blind placebo-controlled study of L-dopa, bromocriptine and pramipexole in healthy subjects. Br J Clin Pharmacol 67:333-340. CrossRef Medline

Mignot E, Nishino S, Guilleminault C, Dement WC (1994) Modafinil binds to the dopamine uptake carrier site with low affinity. Sleep 17:436-437. Medline

Mitchell RJ, Howlett S, Earl L, White NG, McComb J, Schanfield MS, Briceno I, Papiha SS, Osipova L, Livshits G, Leonard WR, Crawford MH (2000) Distribution of the $3^{\prime}$ VNTR polymorphism in the human dopamine transporter gene in world populations. Hum Biol 72:295-304. Medline

Mukovski M, Chauvette S, Timofeev I, Volgushev M (2007) Detection of active and silent states in neocortical neurons from the field potential signal during slow-wave sleep. Cereb Cortex 17:400-414. Medline

Park A, Stacy M (2011) Dopamine-induced nonmotor symptoms of Parkinson's disease. Parkinsons Dis 2011:485063. CrossRef Medline

Rechtschaffen A, Kales A (1968) A manual of standardized terminology, techniques and scoring system for sleep stages of human subjects. Los Angeles: Brain Information Service/Brain Research Institute, University of California.

Rétey JV, Adam M, Gottselig JM, Khatami R, Dürr R, Achermann P, Landolt HP (2006) Adenosinergic mechanisms contribute to individual differences in sleep deprivation-induced changes in neurobehavioral function and brain rhythmic activity. J Neurosci 26:10472-10479. CrossRef Medline

Rétey JV, Adam M, Khatami R, Luhmann UF, Jung HH, Berger W, Landolt HP (2007) A genetic variation in the adenosine A2A receptor gene (ADORA2A) contributes to individual sensitivity to caffeine effects on sleep. Clin Pharmacol Ther 81:692-698. CrossRef Medline
Rusterholz T, Dürr R, Achermann P (2010) Inter-individual differences in the dynamics of sleep homeostasis. Sleep 33:491-498. Medline

Schwierin B, Borbély AA, Tobler I (1996) Effects of N6-cyclopentyladenosine and caffeine on sleep regulation in the rat. Eur J Pharmacol 300:163-171. CrossRef Medline

Spencer TJ, Biederman J, Faraone SV, Madras BK, Bonab AA, Dougherty DD, Batchelder H, Clarke A, Fischman AJ (2013) Functional genomics of attention-deficit/hyperactivity disorder (ADHD) risk alleles on dopamine transporter binding in ADHD and healthy control subjects. Biol Psychiatry 74:84-89. CrossRef Medline

Spielberger CD, Gorsuch RL, Lushene RE (1970) Manual for the State-Trait Anxiety Inventory. Palo Alto, CA: Consulting Psychologist Press.

van de Giessen E, de Win MM, Tanck MW, van den Brink W, Baas F, Booij J (2009) Striatal dopamine transporter availability associated with polymorphisms in the dopamine transporter gene SLC6A3. J Nucl Med 50: 45-52. Medline

van Dyck CH, Malison RT, Jacobsen LK, Seibyl JP, Staley JK, Laruelle M, Baldwin RM, Innis RB, Gelernter J (2005) Increased dopamine transporter availability associated with the 9-repeat allele of the SLC6A3 gene. J Nucl Med 46:745-751. Medline

Vandenbergh DJ, Persico AM, Hawkins AL, Griffin CA, Li X, Jabs EW, Uhl GR (1992) Human dopamine transporter gene (DAT1) maps to chromosome 5p15.3 and displays a VNTR. Genomics 14:1104-1106. CrossRef Medline

VanNess SH, Owens MJ, Kilts CD (2005) The variable number of tandem repeats element in DAT1 regulates in vitro dopamine transporter density. BMC Genet 6:55. CrossRef Medline

Volkow ND, Fowler JS, Logan J, Alexoff D, Zhu W, Telang F, Wang GJ, Jayne M, Hooker JM, Wong C, Hubbard B, Carter P, Warner D, King P, Shea C, Xu Y, Muench L, Apelskog-Torres K (2009) Effects of modafinil on dopamine and dopamine transporters in the male human brain. JAMA 301: 1148-1154. CrossRef Medline

Volkow ND, Tomasi D, Wang GJ, Telang F, Fowler JS, Logan J, Benveniste H, Kim R, Thanos PK, Ferré S (2012) Evidence that sleep deprivation downregulates dopamine D2R in ventral striatum in the human brain. J Neurosci 32:6711-6717. CrossRef Medline

Vyazovskiy VV, Olcese U, Lazimy YM, Faraguna U, Esser SK, Williams JC, Cirelli C, Tononi G (2009) Cortical firing and sleep homeostasis. Neuron 63:865-878. CrossRef Medline

Wisor JP, Nishino S, Sora I, Uhl GH, Mignot E, Edgar DM (2001) Dopaminergic role in stimulant-induced wakefulness. J Neurosci 21:1787-1794. Medline

Wu MN, Koh K, Yue Z, Joiner WJ, Sehgal A (2008) A genetic screen for sleep and circadian mutants reveals mechanisms underlying regulation of sleep in Drosophila. Sleep 31:465-472. Medline 